\title{
Chronic and long-term complications after lung transplant: a narrative review
}

\author{
David Brett Erasmus, Tathagat Narula, Andras Khoor
}

Mayo Clinic, Jacksonville, FL, USA

Contributions: (I) Conception and design: DB Erasmus; (II) Administrative support: None; (III) Provision of study materials or patients: None; (IV) Collection and assembly of data: All authors; (V) Data analysis and interpretation: DB Erasmus, T Narula; (VI) Manuscript writing: All authors; (VII)

Final approval of manuscript: All authors.

Correspondence to: David Brett Erasmus. Mayo Clinic, Jacksonville, FL, USA. Email: erasmus.david@mayo.edu.

Background: The purpose of this article is to provide a current literature overview of long-term complications after lung transplantation (LT) which commonly affect graft survival. Long-term survival after LT is poor compared to that of other solid organ transplants. Understanding entities which influence graft function will lay a platform for new research into prevention and treatment and hopefully translate to improved survival.

Methods: Narrative overview of literature retrieved from searches of computerized databases (predominantly PubMed from 1990 to 2020) and other authoritative texts. The review focused primarily on terms related to chronic lung allograft dysfunction and infections which most commonly lead to graft failure, with an emphasis on current recommendations.

Results: One-year survival after LT has improved significantly. Median survival worldwide is now 6.2 years (improved from 4.3 in the era 1990-1998) and if recipients survive the first year, median survival is 8.3 years. Median survival worldwide over the period 2009-2016 is 6.5 years. Despite these improvements, long-term survival after LT continues to lag survival after other solid organ transplants. Long-term medical complications after LT are diverse and encompass predominantly events related to infections, chronic rejection, malignancy, or sequelae of large airway complications. Complications related to onset and progression of chronic lung allograft dysfunction (CLAD) translates to poor long-term survival and patients remain at risk for infections throughout their post-transplant lives. Furthermore, infection is often a risk factor for CLAD and vice versa. This review provides a brief overview of these entities.

Conclusions: Long-term complications of infection and chronic graft failure continue to limit survival after LT. The last two decades have cast significant light on the etiology and pathogenesis of chronic graft failure.

Keywords: Chronic lung allograft dysfunction (CLAD); lung transplant; transplantation; chronic graft failure; complications

Received: 20 August 2020. Accepted: 05 March 2021.

doi: $10.21037 /$ ccts-20-174

View this article at: http://dx.doi.org/10.21037/ccts-20-174

\section{Introduction}

One-year survival after lung transplantation (LT) has improved significantly. Median survival worldwide is now 6.2 years (improved from 4.3 in the era 1990-1998) and if recipients survive the first year, median survival is 8.3 years. Median survival worldwide over the period 2009-2016 is
6.5 years (1). Despite these improvements, long-term survival after LT continues to lag survival after other solid organ transplants. Long-term medical complications after LT are diverse and encompass predominantly events related to infections, chronic rejection, malignancy, or sequelae of large airway complications (Table 1). Complications 
Table 1 Potential medical complications after lung transplantation Infections (bacterial, fungal, viral, mycobacterial, protozoal):

Early (perioperative), subacute, chronic

Rejection:

Acute (perivascular lymphocytic), Chronic (CLAD phenotypes)

Malignancy:

Post-transplant lymphoproliferative disorder, skin cancer, solid tumors (native lung after single lung transplant), colon cancer in cystic fibrosis)

Cardiovascular:

Hypertension, arrhythmia, accelerated coronary artery disease, venous thromboembolism

Renal and electrolytes:

Acute renal insufficiency, chronic kidney disease, hypomagnesemia

Gastrointestinal:

Gastroesophageal reflux, gastroparesis, esophageal motility, cholestasis, biliary dysfunction.

Hematological:

Anemia, leukopenia, thrombocytopenia

Endocrine disorders:

Steroid induced diabetes, dyslipidemia, gonadal dysfunction, obesity

Musculoskeletal:

Osteoporosis, myopathy

Neurological:

Posterior reversible encephalopathy syndrome (PRES), peripheral neuropathy, tremor, memory loss

Drug reactions:

Calcineurin inhibitor toxicity, multiple drug-drug interactions

related to onset and progression of chronic lung allograft dysfunction (CLAD) translates to poor long-term survival and patients remain at risk for infections throughout their post-transplant lives. Furthermore, infection is often a risk factor for CLAD and vice versa. This review provides a brief overview of these entities, attempting to address the most poignant clinical issues, highlighting where advances have been made and emphasizing where deficits still exist.

We present the following article in accordance with the Narrative Review reporting checklist (available at https:// ccts.amegroups.com/article/view/10.21037/ccts-20-174/rc).

\section{Methods}

A list of search terms was compiled (Table 2) based on clinical experience. PubMed searches were performed using the search term 'lung transplant' and each term. Systematic reviews were separately noted (Table 2) and emphasis placed on search results obtained within the last decade for purposes of this review.

\section{Discussion}

\section{Infectious complications}

\section{Bacterial infections}

In contrast to other solid organs, lung transplant itself is a major risk factor for infections (2). Exposure to environmental insults, compromised cough reflex and impaired muco-ciliary clearance in the setting of denervation all contribute to increasing risk of infections (3-5). Furthermore, infection increased the risk of CLAD which in turn has been deemed a major risk factor for subsequent infection (6).

Infection has been identified as the leading cause of death, accounting for $37 \%$ of cases between 30 days and 1 -year post-lung transplant (7). Bacterial infections are most common, accounting for $35-66 \%$ of cases. Most bacterial infections occur in the immediate postoperative period (first 2 weeks) with the vast majority localized to the lungs, mediastinum, or pleural space (8-11). Complicated surgical site infections, including empyema, surgical wound, mediastinitis, sternal osteomyelitis and pericarditis occur in approximately $5 \%$ of patients within the first month, with a mean onset 25 days post-transplant and may contribute significantly to decrease in 1 year survival. Pleural space infections occur in up to $27 \%$ of cases with Candida albicans being the most frequent culprit (12). Methicillin resistant Staphylococcus aureus (MRSA), Pseudomonas aeruginosa (PsA) and other gram-negative bacteria predominate in the first 6 months, with Nocardia sp., Listeria and Pneumocystis firovecii occurring occasionally during this period (2). Pneumonia is the most common presenting infectious clinical manifestation after lung transplant. In the early period ( $<30$ days), health care associated pathogens PsA (33\%), MRSA (26\%), Acinetobacter (16\%) and Aspergillus $s p$. predominate, while community acquired pathogens $S$. Pneumoniae, Legionella and viral infections are the most frequent culprits beyond 6 months (13).

Bacterial infections portend a lower mortality than fungal 
Table 2 Long-term complications commonly affecting lung allograft function

\begin{tabular}{|c|c|c|c|c|}
\hline $\begin{array}{l}\text { PubMed search term: "lung transplant" + } \\
\text { term below }\end{array}$ & $\begin{array}{l}\text { Search } 1 / 1 / 1990 \\
\text { to } 11 / 6 / 2020\end{array}$ & $\begin{array}{l}\text { Systematic review } \\
1 / 1 / 1990 \text { to } 11 / 6 / 2020\end{array}$ & $\begin{array}{c}\text { Search } 11 / 6 / 2010 \text { to } \\
11 / 6 / 2020\end{array}$ & $\begin{array}{l}\text { Systematic review } \\
11 / 6 / 2010 \text { to } 11 / 6 / 2020\end{array}$ \\
\hline \multicolumn{5}{|l|}{ Infection } \\
\hline Pseudomonas sp. & $\mathrm{n}=507$ & $\mathrm{n}=0$ & $n=263$ & $\mathrm{n}=0$ \\
\hline Nocardia & $n=138$ & $n=0$ & $n=55$ & $\mathrm{n}=0$ \\
\hline Mycobacteria & $n=356$ & $n=2$ & $n=216$ & $n=2$ \\
\hline \multicolumn{5}{|l|}{ Viral } \\
\hline \multicolumn{5}{|l|}{ Fungal } \\
\hline Aspergillus sp. & $\mathrm{n}=776$ & $\mathrm{n}=4$ & $n=311$ & $\mathrm{n}=4$ \\
\hline Scedosporium sp. & $\mathrm{n}=87$ & $\mathrm{n}=0$ & $\mathrm{n}=51$ & $\mathrm{n}=0$ \\
\hline \multicolumn{5}{|l|}{ Chronic rejection } \\
\hline Chronic lung allograft dysfunction & $n=885$ & $\mathrm{n}=7$ & $n=649$ & $\mathrm{n}=7$ \\
\hline Bronchiolitis obliterans syndrome & $n=2555$ & $n=15$ & $n=708$ & $\mathrm{n}=9$ \\
\hline Restrictive allograft syndrome & $\mathrm{n}=127$ & $\mathrm{n}=1$ & $n=119$ & $\mathrm{n}=1$ \\
\hline
\end{tabular}

or viral infections but in terms of actual numbers, account for more total deaths $(14,15)$. Data on outcomes secondary to bacterial colonization is contradictory. Shteinberg et al. reported a relative risk for mortality of $9.2 \%$ in LT recipients colonized with fluoroquinolone resistant gramnegative bacilli (16). Others have reported that colonization with multi-drug resistant or pan-resistant organisms does not increase risk of infection or impact survival $(17,18)$.

Genetic factors may affect outcome. Toll-like receptor 4 (TLR4) polymorphisms associated with endotoxin hyporesponsiveness have been linked to significantly lower risk for acute rejection in the first 3 years and a trend towards decreased onset of grade 2 or 3 CLAD. Genetic deficiency of pentraxin 3 (PTX3), a soluble pattern recognition receptor, is known to effect tuberculosis and PsA colonization in patients with $\mathrm{CF}$, and predispose to invasive aspergillosis (19).

\section{Special considerations}

Patients with CF colonized with PsA, MRSA or Aspergillus $s p$. are not at greater risk for infectious complications than non CF patients (9). Burkholderia Cepacia complex and in particular genotype Cenocepacia has been deemed an absolute contraindication to transplantation at some centers due to poor outcomes reported in earlier series(20). However, single center reports of equivalent outcomes have recently challenged this paradigm (21).

Mycobacterial infections appear to be on the rise. Mycobacterium Abscessus is of particular concern and may cause disseminated disease. Skin lesions are the most common clinical presentation in solid organ transplantation, 
but in lung transplant recipients, pleuro-parenchymal disease is more common. Most centers recommend initiating therapy for non-tuberculous mycobacterial disease pre-transplant if clinical and radiographic findings suggest active infection (22).

Nocardia frequently occurs in the native structurally damaged lung of single lung transplant recipients. Infection with Nocardia, while rare (0.6-2.1\%) carries increased mortality (up to $75 \%$ ) in lung transplant recipients with $N$. farcinica being a particularly virulent strain. Trimethoprimsulfamethoxazole (TMP-SMX) prophylaxis does not necessarily preclude the diagnosis since TMX-SMX resistant strains exist. Nocardia notoriously mimics other pathogens and should be considered in all cases of pneumonia not responding to conventional antibiotics $(23,24)$.

\section{Viral infections}

Respiratory viruses, herpesvirus infections, hepatitis viruses, polyomaviruses and parvovirus require attention in this population group. This review will focus on viruses that are most likely to affect allograft function (25).

\section{Respiratory viruses}

Respiratory viral infections often lead to an ominous course in lung transplant recipients and may precipitate a permanent decline in lung function, either directly or as a precipitant to chronic rejection. Most common culprits belong to the families Orthomyxoviridae (influenza A \& B), Paramyxoviridae (respiratory syncytial virus/ RSV, parainfluenza, human metapneumovirus), picorna viruses (rhinovirus, enterovirus) and adenovirus (26,27). Additionally, the impact of the recent SARS corona virus (SARS CoV) pandemic on lung transplant recipients requires attention. SARS $\mathrm{CoV}$ is addressed in a separate chapter. Respiratory virus infections can occur at any time after transplant or be transmitted from donor organs.

Immunosuppression may significantly prolong the clinical course. Rhinovirus particles have been recovered 15 months after the initial infection in LT recipients (28). The yield of recovering virus/viral particles is significantly higher in symptomatic (34-66\%) than asymptomatic individuals $(3-5 \%)$. In pediatric transplant recipients, younger age is associated with increased risk, but in the adults, neither age, type of transplant or underlying diagnosis appear to increase risk $(25,29,30)$. Controversy exists regarding respiratory viral infections as a potential precipitant for acute cellular rejection (ACR). One study suggests an association, whereas several others (albeit with significant design flaws) do not (29,31-33). However, there appears to be a strong epidemiological link between viral infection and development of chronic rejection/ CLAD. Retrospective studies suggest subsequent CLAD development in up to $60 \%$ of cases following a community acquired respiratory virus (CARV) infection, with infection in the first year carrying additional long-term increased risk $(29,34,35)$. Limited data suggests that "non-rhinovirus" infection and RSV appear to have an increased association with development of CLAD compared to human metapneumovirus (36,37).

Treatment of respiratory viral infections depends on etiology. Early intervention for influenza following current guidelines shows clear benefit in terms of outcomes (38). Treatment options for RSV include ribavirin (oral, intravenous, or inhaled) with or without incremental steroid doses and intravenous immunoglobulin (IVIG) (39). Data supporting this approach stems from case series. $\mathrm{Li}$ et al. evaluated 21 cases comparing oral $(\mathrm{n}=6)$ vs. inhaled ribavirin $(\mathrm{n}=21)$. This retrospective study showed no difference in outcomes between inhaled or oral ribavirin groups at 6 months post infection (40). Observational studies with RSV-specific humanized monoclonal antibody, Palivizumab suggest that it is well tolerated in lung transplant recipients albeit without any reduction in severity of illness or mortality benefits (41). Treatment of RSV infection with ALN-RSV01, a small interfering RNA, administered as inhalation therapy which targets viral replication has shown a trend towards a decrease in new or progressive bronchiolitis obliterans syndrome (BOS). Treatment efficacy was enhanced when therapy was started within 5 days of symptom onset (42). Limited data suggests successful treatment of Adenovirus infection with Cidofovir and IVIG (43). Rhinovirus, the most frequently isolated respiratory virus in lung transplant recipients, does not currently have any effective treatment options.

\section{Herpesviridae}

The herpesviridae family of viruses, including cytomegalovirus (CMV) and Epstein Barr virus (EBV) are the most commonly associated viruses causing infection related complications after LT. Infection can occur by donor transmission, reactivation, or primary natural infection. $\mathrm{CMV}$ or EBV donor sero-positive to recipient $\mathrm{CMV}$ or $\mathrm{EBV}$ sero-negative recipients are at significantly higher risk than seropositive recipients. CMV pneumonitis is a major risk factor for onset of CLAD while EBV viremia carries risk for development of post-transplant lymphoproliferative disorder. Cytomegalovirus (CMV)

$\mathrm{CMV}$ infection is defined as replication of virus detectable 


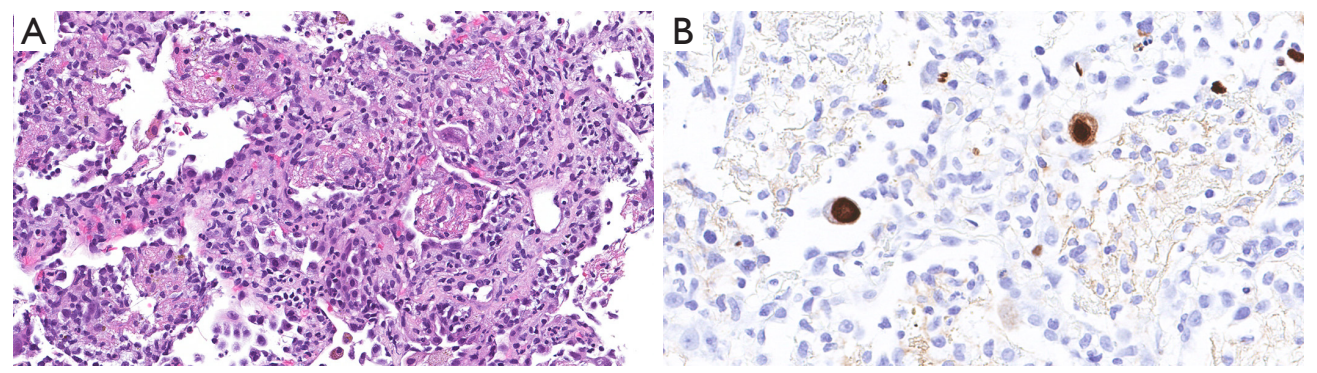

Figure $1 \mathrm{CMV}$ pneumonia. (A) CMV pneumonia with alveolar septal thickening and intraalveolar fibrin balls (HE stain, original magnification $\times 200$ ); (B) immunohistochemistry reveals nuclear CMV inclusions (original magnification $\times 400$ ). CMV, cytomegalovirus.

by nucleic acid testing or antigenemia regardless of symptoms, whereas CMV disease implies infection with attributable symptoms (Figure 1). The main risk factors for CMV disease relate to donor-recipient serostatus (D+/R-), induction immunosuppression with lymphocyte depleting agents and enhanced immunosuppression to treat acute rejection episodes (44). The incidence of CMV disease in lung transplant recipients varies from $5 \%$ to $40 \%$ (44-46). CMV disease incidence is higher in lung transplant recipients compared to other solid organ recipients. However, in the current era of routine CMV prophylaxis, the incidence of CMV pneumonia is low. In two prospective cohorts, CMV replication in allografts (measured by PCR) was $41 \%$ and $44 \%$ at 1 year, however, pneumonitis developed in only $5-8 \%(47,48)$. Due to improved treatment and preventive strategies, mortality from CMV is rare. A significant concern in lung transplant recipients with CMV infection, is the potential for development of CLAD (45). CMV has been identified as a significant risk factor for CLAD in an Australian study (HR =2.1, $\mathrm{P}=0.003$ ) (48). A Swedish study demonstrated that both CMV disease and CMV infection resulted in lower BOS-free survival (32\% and 36\%) vs. 69\% in patients without CMV infection (49).

The optimal length of antiviral prophylaxis is unknown, but most studies have demonstrated prophylaxis less than 6 months to be associated with an increased incidence of CMV disease (50). A randomized trial comparing CMV prophylaxis for 3 months to 12 months revealed incidence of CMV disease was $32 \%$ vs. $4 \%$ respectively $(\mathrm{P}<0.001)(49)$. Notwithstanding, a duration of at least 6 months prophylaxis for the intermediate risk group (D-/R+) appears to be adequate (50). Some centers have employed a combination of CMV specific IVIG in addition to antiviral drug prophylaxis. This approach has not yet been validated to provide additional benefit. Our lung transplant group favors prophylaxis for a minimum 6 months in the intermediate group $(\mathrm{R}+)$ and lifelong in the high-risk group $(\mathrm{D}+/ \mathrm{R}-)$. We discontinue prophylaxis in the latter group if seroconversion to $\mathrm{R}+$ occurs after the first year.

Therapeutically, oral valganciclovir has good bioavailability, providing adequate treatment for mild to moderate disease, but IV ganciclovir is preferred for severe cases with end-organ involvement. Following treatment, subsequent prophylaxis is generally recommended for 4 to 8 weeks to prevent relapse $(51,52)$. Lung transplant patients are also at high risk of antiviral resistance. Most mutations coding for antiviral resistance reside in UL97 kinase or UL 54 polymerase. UL 97 resistance can usually be overcome by increasing the dose of ganciclovir, while UL 54 mutations require alternative antiviral treatment, typically with Foscarnet. Newer antiviral agents, letermovir and brincidofovir have not been fully evaluated in lung transplant recipients. Letermovir has recently been approved for CMV prophylaxis after hematopoietic stem cell transplantation. Veit et al. recently reported successful rescue therapy with Letermovir in 4 lung transplant recipients who were failing conventional therapy (53). The oral agent brincidofovir has demonstrated anti-CMV activity with decreased overall CMV DNAemia in posthematopoietic stem cell transplant recipients, but failed to decrease clinically significant disease or DNAemia in a recent phase 3 trial (54). The mTOR inhibitor, sirolimus has a theoretical antiviral advantage compared to other immunosuppressants. In kidney transplant recipients, substitution of sirolimus for mycophenolate has been successfully employed in patients suffering recurrent CMV viremia without provoking rejection (55).

\section{EBV}

EBV is a Herpesvirus that infects more than $95 \%$ of the world's population, predominantly children and young adults. Infection frequently is asymptomatic but may manifest as a viral syndrome with adenopathy and fever 
(infectious mononucleosis). Post-transplant primary infections range from an infectious mononucleosis type syndrome (more common in children) to monoclonal lymphocyte proliferation and possible high-grade lymphoma (56). Post-transplant lymphoproliferative disorder (PTLD) is on this spectrum of disorders and occurs due to lack of surveillance of EBV infected B-lymphocytes due to immunosuppression. Lymphocyte depleting induction agents typically increase the risk, especially in seropositive donors to seronegative recipients (D+/R-) (57). The m-TOR inhibitor sirolimus protects against proliferation of EBV infected cells in animal models and may play a protective role in transplant recipients. $(58,59)$ Some centers have employed ganciclovir prophylaxis in high risk EBV mismatch (D+/R-) cases based on in-vitro activity against EBV. However, agents such as acyclovir or ganciclovir act only on lytic virus and have no activity against latently infected $B$ cells and are hence ineffective for treatment of EBV DNAemia (61). Since these patients are at highest risk of developing PTLD, they would intuitively be potential candidates for a reduction in immunosuppression, possible antiviral or anti-lymphocyte B-cytotoxic therapy (56). Administration of the anti-CD20 monoclonal antibody rituximab has been shown to be effective in controlling EBV DNAemia and PTLD in patients undergoing allogeneic hematopoietic stem cell transplants (HSCT) (60). Simply lowering immunosuppression in pediatric liver transplant recipients with EBV DNAemia has been shown to result in significantly lower PTLD (63). Some groups have shown efficacy in lowering EBV DNAemia by administering autologous or allogeneic EBV-specific cytotoxic T cells after HSCT after lowering immunosuppression had proven ineffective. This strategy, however, has not been effective after solid organ transplantation (61).

In summary, treatment of EBV related PTLD still requires reduction of immunosuppression as a first step, followed by therapy with rituximab or chemotherapy if ineffective or in cases of aggressive PTLD. (56) EBV specific cytotoxic T-cell infusions can be tried if there is no response to other measures.

\section{Mold infection}

Mold accounts for approximately $70 \%$ of invasive fungal infections after lung transplant and the cumulative risk in the first year after transplant is $8.6 \%$. LT recipients are at increased risk of mold infections due to direct environmental exposure, impaired mucociliary clearance, denervation and colonization of the airway or native lung after single LT (62). Aspergillus and Scedosporium spp account for up to $73 \%$ and $27 \%$ of these infections respectively. Factors associated with increased risk include increased immunosuppression, neutropenia, anti-lymphocyte induction (particularly OKT3), prior CMV infection, single LT, environmental exposures such as farming, gardening, composting, marijuana smoking and known airway colonization pre-transplant.

\section{Aspergillus}

Aspergillus is the most common cause of invasive fungal infection (IFI) after LT. Predisposing factors are noted above. The association between CMV infection and invasive aspergillosis (IA) has been well documented but the mechanism remains unclear. Pre-transplant colonization with Aspergillus sp. increases the risk of IA fourfold post-transplant. In patients who have undergone stem cell transplant, genetic deficiency of PTX3, a soluble pattern recognition receptor, has been found to increase the risk of both CMV and Aspergillosis. Of note, $60 \%$ of patient with cystic fibrosis, one of the significant etiologies for end stage lung disease requiring LT, may be colonized with Aspergillus sp. $(63,64)$.

Aspergillus may present with diverse clinical presentations. These include colonization (up to 46\%), tracheabronchitis $(<1 \%)$, invasive pulmonary aspergillosis (IPA) or disseminated disease. Colonization usually develops within the first 3 months after transplant. This presentation typically represents a benign course. However, without appropriate prophylaxis there is an 11-fold increase for subsequent IPA. CLAD has also been associated with colonization with conidia producing $(<3.5 \mu \mathrm{m})$ species (A. fumigatus, $A$. nidulans, A. terreus, A. flavipes) (65-67). Tracheobronchitis from aspergillosis is rare. It has a median onset 2.7 months post-transplant. The diagnosis can be confounded by presence of ischemic necrosis, especially when it occurs close to the bronchial anastomotic line $(68,69)$. The clinical presentation includes ulcers, necrosis, or pseudo-membranes in the presence of positive microbiology. Outcomes are generally favorable, but occasionally lead to airway stenosis, bronchial dehiscence, bronchopleural fistulas, or fatal hemorrhage (69). IA accounts for $93 \%$ of IFI, with a median onset 10.5 months post-transplant. Patients may present with dyspnea (65\%), cough (58\%) and sputum production (42\%). Less than one third of cases present with fever. Occasionally, patients present with pleuritic chest pain or hemoptysis due to infarction (64). Disseminated disease occurs in approximately $4 \%$ of cases. Dissemination occurs most 


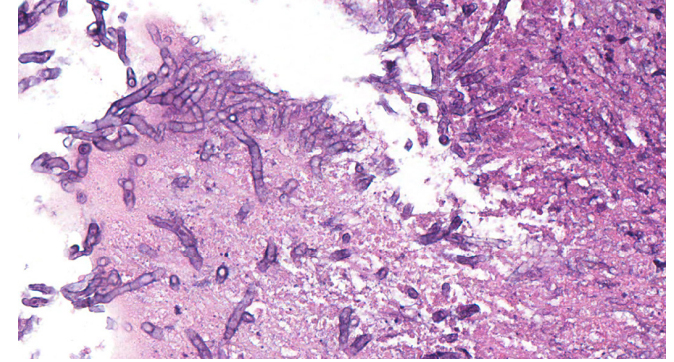

Figure 2 Bronchial wall with necrosis and fungal organisms, consistent with Aspergillus species (HE stain, $\times 200$ ).

commonly to skin, the gastrointestinal tract, endovascular (including endocarditis) or bone. CNS dissemination portends a poor prognosis (70).

The distinction between colonization and infection poses diagnostic challenges. The European Organization for Research and Treatment of Cancer/Mycoses Study Group (EORTC/MSG) has attempted to standardize definitions of invasive fungal infections (IFI) for research and clinical trials. They have proposed "proven", "possible" and "probable" categories. Proven IFI requires histopathological identification of an invasive fungal infection or positive culture from a normally sterile site. Probable IFI require host factors and presence of radiological or mycological criteria. Those who do not meet the mycological criteria are considered "possible IFI".

Mycological criteria include mold recovered by culture, detection of microscopic fungal elements or galactomannan antigen, aspergillus antigen in plasma, bronchoalveolar lavage or cerebrospinal fluid (CSF), or PCR positive testing at similar sites (Figure 2). Newer PCR assays are useful to detect species of Aspergillus as well as mutations associated with azole resistance (71). Classic radiological criteria for IA include dense well circumscribed lesions \pm a halo sign (nodular mass surrounded by ground-glass opacity caused by localized infarction) or cavitation on CT (72). The International Society for Heart and Lung Transplantation (ISHLT) has also published definitions for IFI in lung transplant recipients (69). Plain chest X-ray is neither sensitive nor specific to detect pulmonary infection in the lung transplant population group. Furthermore, the "halo sign" is seldom seen in non-neutropenic solid organ transplant recipients. In patients with proven or probable IFI, bronchial wall thickening and centrilobular opacities with tree-in-bud are the most common findings (73).

Treatment, as for other infections, should be two- pronged, including reduction in IS and addition or escalation of antifungal therapy. Attention should be paid to special circumstances, for instance TBA requires inhaled and systemic antifungal therapy. Anastomotic dehiscence may require stent placement and/or surgical intervention. Voriconazole remains the first line therapy for IA, providing better results than conventional amphotericin B both in response rate $(53 \%$ vs. $32 \%)$ and lower mortality rate (29 vs. $42 \%)(74)$. Amphotericin B and its lipid formulations are considered "alternative" treatments for IA. Voriconazole is notorious for drug-drug interactions due to its effect at cytochrome p450 2C19, CYP 2C9 and CYP34A. Most common side-effects include visual disturbances $(20 \%)$, hepatic dysfunction (12-20\%) and photosensitivity. The echinocandins (caspofungin, anidulafungin and micafungin) also demonstrate activity against aspergillus. At our center, we will consider adding caspofungin to voriconazole in severe cases of IA. Posaconazole has excellent in vitro activity and a favorable safety profile but also interacts with CYP34A, necessitating careful surveillance for drug-drug interactions (75). Prophylactic regimens vary. At our center, we use a combination of echinocandin (caspofungin) and inhaled amphotericin prophylaxis early after transplant and transition to oral itraconazole, reserving voriconazole and posaconazole for treatment of infections due to their higher incidence of side effects.

\section{Scedosporium}

Overall, the four ubiquitous species of Scedosporium, S. apiospermum, S. boydii, S.aurantiacum and S. prolificans account for up to $27 \%$ of mold infections after LT, with a median occurrence 12 months after transplant. Colonization occurs in $8 \%$ of patients with cystic fibrosis, increasing the risk of invasive disease in this population group $(76,77)$. Clinical presentations include colonization, sinopulmonary disease, mycetoma and disseminated disease with central nervous system involvement. Almost $50 \%$ develop disseminated disease. The radiographic and histopathological findings are indistinguishable from aspergillus, but with higher relapse rates and higher resistance to antifungal therapy (77). Scedosporium is inherently resistant to amphotericin $\mathrm{B}$, with variable resistance to itraconazole, posaconazole, voriconazole and micafungin. Voriconazole is the agent most active against Scedosporium sp, either alone or in combination (78). S. Prolificans is particularly resistant. The combination of voriconazole and terbinafine has proven successful in treating a case presenting with brain abscess (79). Overall 


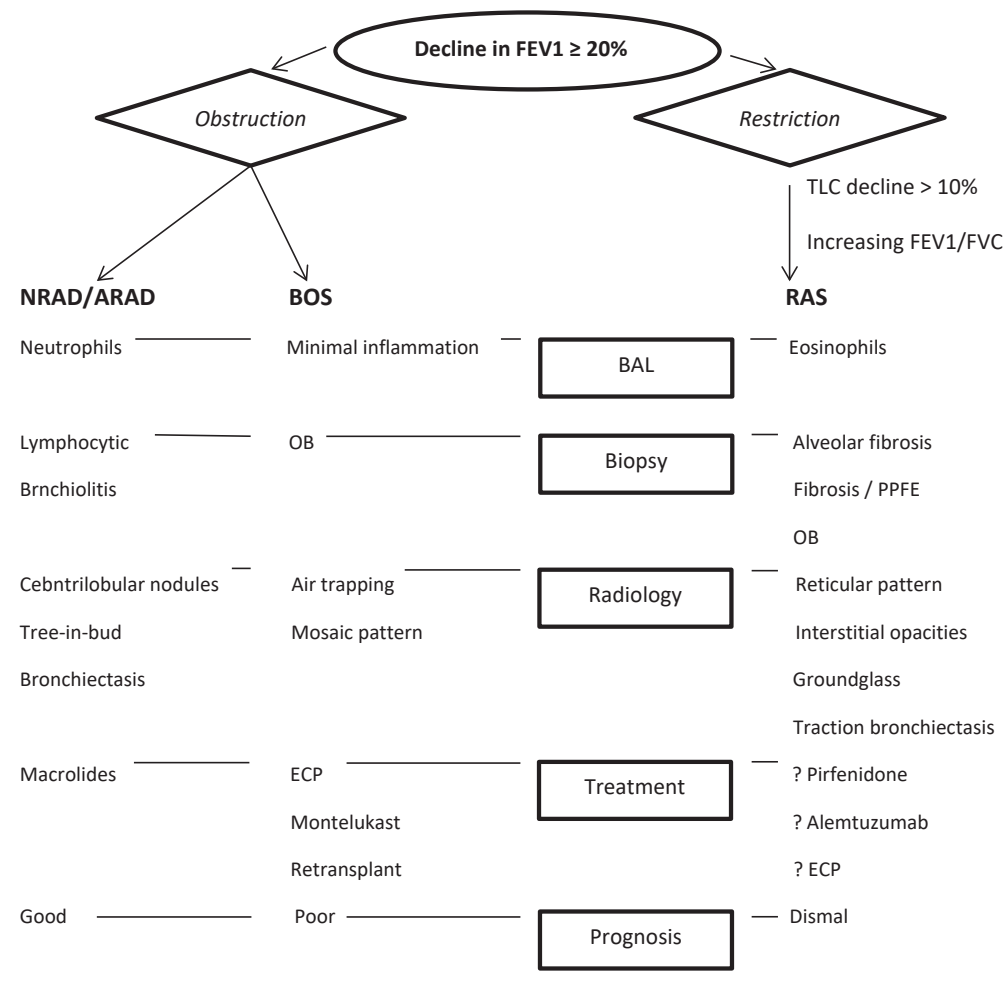

Figure 3 CLAD phenotypes. FEV1, forced expiratory volume in 1 second; NRAD, neutrophil reversible allograft dysfunction; ARAD, azithromycin reversible allograft dysfunction; BOS, bronchiolitis obliterans syndrome; ECP, extracorporeal photopheresis; TLC, total lung capacity; FVC, forced vital capacity; RAS, restrictive allograft syndrome; BAL, bronchoalveolar lavage; OB, obliterative bronchiolitis; PPFE, pleuroparenchymal fibroelastosis.

prognosis is poor, especially with dissemination, with reported mortality ranging 54-78\% (80).

Although infrequent, lung transplant recipients are also at risk for a variety of other mold infections, including dematiaceous molds, Zygomycosis (previously called mucormycosis), and endemic mycosis (histoplasmosis, blastomycosis and coccidiomycosis) which may be prevalent in certain geographic zones. Additionally, yeast infections, particularly Candida sp are responsible for $23 \%$ of all invasive fungal infections (81).

\section{$C L A D$}

The true incidence of CLAD is unknown considering inconsistencies of definitions over different time periods, selection bias in reported mortality from single centers, and cause of death being defined as 'graft failure' vs. BOS in registries. Although one -year survival has improved steadily over the past 2 decades, improvement in long-term survival after LT has not followed suit (82). CLAD remains the most significant barrier to long-term survival after LT.
Bronchiolitis obliterans syndrome (BOS) and restrictive allograft syndrome (RAS), representing obstructive and restrictive pathophysiology respectively, are now widely accepted clinical phenotypes falling under the umbrella term 'CLAD'. Most studies predate separation of CLAD into phenotypes. Additionally, the entity of neutrophil reversible allograft dysfunction (NRAD), also termed azithromycin responsive allograft dysfunction (ARAD) has been separately defined under the CLAD umbrella (Figure 3) (83,84). Frequently, patients may present with features of predominantly one or a combination of these phenotypes. CLAD staging is based on decline in FEV1, which applies to both BOS and RAS (85). For the purposes of discussion, we will discuss each phenotype separately.

\section{Bronchiolitis obliterans syndrome (BOS) phenotype} BOS after LT is the surrogate term for the clinical entity representing the underlying pathological finding of bronchiolitis obliterans (BO or OB). Clinically, the diagnosis requires at least a $20 \%$ decline in FEV1 compared to the mean of the 2 best FEV1 values (taken at least 
3 weeks apart) after transplant (Table 3). It also requires exclusion of confounding factors such as infection, acute rejection, large airway complications or recurrent native disease. The pathogenesis of BOS is still poorly understood and mortality is high (Figure 4A) (86).

Clinical factors associated with a higher risk for rapid decline include female sex, underlying diagnosis of IPF and single LT. Onset within the first 3 months is associated with particularly poor survival $(87,88)$. Prominent risk factors for BOS include allo-immune factors, primary graft dysfunction, gastro-esophageal reflux disease (GERD), infection, BAL neutrophilia (16-24\% threshold), single vs. bilateral LT ( $49 \%$ vs. $32 \%$ respectively in a review of 225 patients) and medication non-compliance (89-91).

BOS is commonly associated with the severity of acute rejection episodes, either perivascular (grade A) or peribronchiolar (grade B). Grade A2 or higher rejection episodes correlate well with development of BOS in many studies (92-94). Recurrent A1 rejection episodes may also predict the syndrome, a finding which has therapeutic

Table 3 CLAD: severity for BOS or RAS

\begin{tabular}{ll}
\hline CLAD GRADE & FEV1 \% of baseline \\
\hline 0 & $>90 \%$ and FEF $25-75 \%>75 \%$ \\
Op & $81-90 \%$ and FEF $25-75 \%<75 \%$ \\
1 & $66-80 \%$ \\
2 & $51-65 \%$ \\
3 & $\leq 50 \%$ \\
\hline
\end{tabular}

Data from Verleden et al. (85). CLAD, chronic lung allograft dysfunction; BOS, bronchiolitis obliterans syndrome; RAS, Restrictive allograft syndrome; FEV1, forced expiratory volume in 1 second. implications (95). Lymphocytic bronchiolitis or grade B rejection is also cited as a risk factor for development of BOS. Consequently, treatment of greater than minimal risk (grade A or B) acute rejection remains uncontroversial due to a strong link between $\geq \mathrm{A} 2$ rejection with BOS. Over the past two decades, ISHLT, ERS, and ATS guidelines have instituted guidelines which recommend treatment of clinically significant A1 rejection (96,97).

Pathophysiologically, animal studies (and limited human studies) suggest sensitization may take place due to exposure of collagen $\mathrm{V}$ in epithelium of small airways. Auto-antibodies to Ka1-tubulin has also been linked to the pro-fibrotic process of BO $(98,99)$. Other risk factors with a strong correlation include GERD (both acid and nonacid reflux) $(92,93)$ and viral infections, particularly CMV which can also cause $\mathrm{BO}$ in a non-transplant setting. CMV pneumonitis in the first 6 months portends a poor prognosis in terms of BOS onset and mortality (100). Community acquired respiratory virus infections (particularly RSV and influenza), bacterial respiratory infections, especially Pseudomonas sp. and aspergillus infections have all been linked to development BOS $(25,26,31,66,101)$.

Several potential surrogate markers for BOS have been studied but so far, but none have proved superior to pulmonary function testing. Broncho-alveolar lavage (BAL) parameters associated with pro-inflammatory state (IL-8, neutrophilia, chemokine monocyte chemoattractant protein 1/MCP-1), markers of innate immunity (alpha defensins), enzymes linked to neutrophil migration and extracellular matrix remodeling (matrix metalloproteinase/MMP-9) and markers of oxidative stress (myeloperoxidase and glutathione) have all been implicated in the development of BOS (102-107).

Diagnosis by CT has gained traction, particularly after

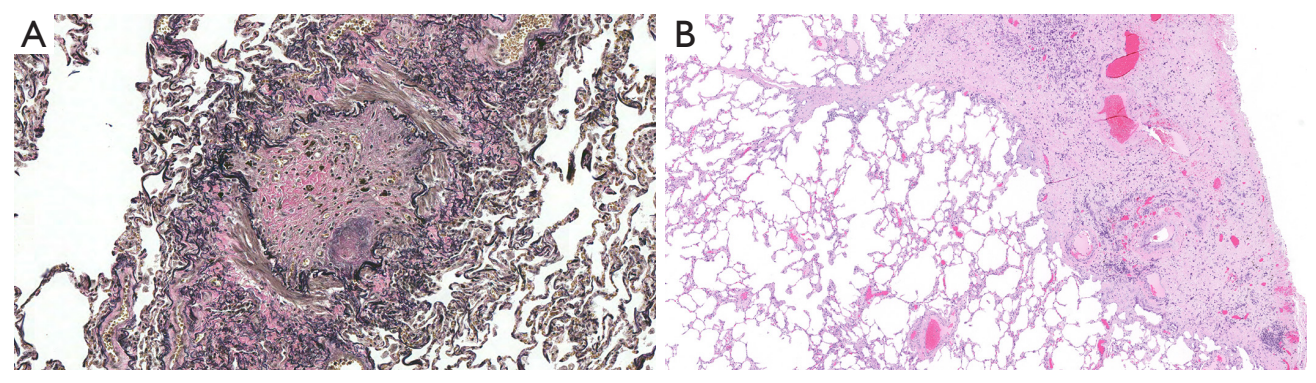

Figure 4 Histopathologic correlates of CLAD. (A) Obliterative bronchiolitis. The lumen of a bronchiole is completely obliterated by scar tissue and can only be recognized by a Verhoeff-Van Gieson stain, which highlights its elastic layer $(\times 100)$. (B) Pleuro-parenchymal fibroelastosis showing subpleural elastotic fibrosis with abrupt transition to the unaffected alveolated parenchyma (HE stain, $\times 20$ ). CLAD, chronic lung allograft dysfunction. 
pediatric LT, where lung function testing may be less reliable. Typical findings on CT scan imaging include air-trapping on expiratory images, bronchiectasis, and a mosaic pattern. Although air-trapping correlates more strongly with BOS than other CT findings, this finding is not sufficiently accurate to predict onset of BOS before spirometry (108-112).

The therapeutic landscape for medical management of BOS is relatively barren. There is no clear evidence to suggest that any particular immunosuppressive regimen is superior for BOS prevention. High dose steroids ( $>30 \mathrm{mg}$ daily prednisone) are also not recommended due to significant side-effects and lack of superior outcomes. Most centers will switch cyclosporine to tacrolimus if relevant, due to a clinical trial showing slower progression of BOS with tacrolimus (113). Adding macrolides for antiinflammatory effect may be beneficial for both preventing or treating BOS, particularly in patients with neutrophil predominant disease characterized by BAL neutrophilia $>15 \%$ and associated peri-bronchial infiltrates with treein bud appearance $(114,115)$. Our group favors starting azithromycin $250 \mathrm{mg}$ three times a week for CLAD prophylaxis early after LT.

All patients with BOS should be evaluated for GERD. Recommendations for gastric fundoplication after transplant are based on several studies in patients with GERD and BOS which identified GERD as a risk factor $(116,117)$. Early fundoplication ( $<3$ months post lung transplant) has been associated with freedom from BOS and improved 1and 3-year survival $(118,119)$. Complications of bleeding, gastric perforations and dysphagia have been reported in $5-25 \%$ of patients after fundoplication. The optimal timing and patient selection require careful consideration (119).

Patients with scleroderma, a connective tissue disease that can result in pulmonary pathology necessitating LT, require special consideration. This disease affects the proximal gastrointestinal tract in $90 \%$ of cases (120). Esophageal dysfunction, delayed gastric emptying and GERD with micro-aspiration increases the risk of BOS. Esophageal dysfunction may increase the risk or contraindicate Nissen fundoplication due to risk of anterograde emptying of the esophagus. Some scleroderma patients may be amenable to Dor (partial) fundoplication while some centers employ Roux-en-Y bypass for reflux control. Despite these limitations, patients with scleroderma appear to have similar outcomes after LT $(121,122)$.

Enhanced immunosuppression strategies using lymphocyte depleting agents Alemtuzumab, thymoglobulin or total lymphoid irradiation have suggested benefit by reducing the rate of decline of FEV1 in patients with BOS, but these findings have not been pursued in prospective clinical trials (123-127). Extracorporeal photopheresis (ECP) incubates a patient's peripheral blood monocytes with 8-methoxypsoralen, irradiates the cells, and reinfuses them into the patient. This treatment has an immunomodulatory effect on peripheral blood monocytes and has been associated with a decrease in decline of lung function in patients with BOS. Patients with refractory BOS who stabilized after ECP have been shown to have higher levels of $\mathrm{CD} 4^{+} \mathrm{CD} 25^{+}$regulatory $\mathrm{T}$ cells than those who were unresponsive, suggesting a mechanism whereby this therapy may work (128). Studies with ECP in BOS have shown an increase in anti-inflammatory and decrease in pro-inflammatory cytokines. Several nonrandomized or retrospective studies have suggested clinical and physiologic benefit, but good quality randomized controlled trials are lacking (129). Our program employs a treatment trial of ECP for onset of mild CLAD. A recent trial of montelukast, a cysteinyl-leukotriene type 1 receptor antagonist, administered to 153 patients (115 with BOS and 38 with RAS) showed significant attenuation in rate of FEV1 decline after 3 and 6 months $(\mathrm{P}<0.0001)$ and this translated to better progression free $(\mathrm{P}<0.0001)$ and overall survival $(\mathrm{P}=0.0002)(130)$.

Re-transplantation is a last resort. Selected patients may have good outcomes. Overall, survival after retransplantation is inferior to primary LT. Survival at one year is approximately $60-78 \%$, with median survival over the past 2 decades of approximately only 2 years. The primary reason for mortality in these patients relates to infection in a retained allograft. For this reason, we suggest re-transplanting the rejected allograft or bilateral lung retransplantation $(131,132)$.

\section{Restrictive allograft syndrome (RAS)}

In a 1985 report, lung specimens were obtained from 5 heart-lung recipients ( 2 by autopsy, 2 by open lung biopsy and 1 by re-transplantation). Pathology revealed extensive bronchiolitis obliterans, interstitial, and pleural fibrosis, and accelerated arterial and venous arteriosclerosis. At the time, the conclusion was that BO may be associated with heart-LT. Little was made of the fibrotic changes (133). Similarly, in 2006, a study revealed varying degrees of $\mathrm{BO}$ as well as interstitial fibrosis in 2 of 12 patients from specimens obtained at re-transplantation (134). Pakhale et al. studied a 1990 to 2002 cohort of 686 patients from Duke and Toronto. They discovered upper lobe fibrosis 
in 13 of 686 patients $(1.9 \%)$ as a novel presentation of chronic allograft dysfunction in lung transplant recipients, differentiated from bronchiolitis obliterans syndrome based on physiologic and radiologic findings.

The restricted phenotype (TLC decline of $\geq 10 \%$, in addition to FEV1 decline of $\geq 20 \%$ ) with associated pleuroparenchymal radiographic changes were found to have a poor prognosis (Figure 4B) compared to the predominantly obstructive phenotype without radiographic changes $(135,136)$. Some reports describing RAS have not routinely used TLC, but rather simultaneous FEV1 and FVC decline to define restriction, but with similar poor survival (8 vs. 36 months). The most common radiographic findings include interstitial opacities, traction bronchiectasis, architectural distortion and ground-glass opacities (136). Micro-CT (2 mm cuts) and matched histopathology has shown RAS to be associated with greater destruction of both pre-terminal and terminal bronchioles. Also, the interstitial compartments expand and alveolar airspaces are obliterated by accumulation of fibrous connective tissue (83).

Risk factors for RAS remain elusive. Colonization and pseudomonas infection, BAL neutrophilia, lymphocytic bronchiolitis and significant ( $\geq \mathrm{A} 2$ ) rejection episodes appear common to both RAS and BOS. However, lymphocytic bronchiolitis $(\mathrm{P}=0.031)$ and $\mathrm{BAL}$ eosinophilia ( $\geq 2 \%$ ) appear more strongly associated with RAS (137). Differential regulation of cytokines including interleukin (IL)-1beta $(\mathrm{P}<0.01)$, IL-1Ralpha $(\mathrm{P}<0.001)$, IL-6 $(\mathrm{P}<0.001)$, IL-8/CXCL8 ( $\mathrm{P}<0.001)$, IP-10/CXCL10 ( $<<0.05)$, MCP-1/ CCL2 $(\mathrm{P}<0.05)$, macrophage inflammatory protein (MIP)1alpha/CCL3 $(\mathrm{P}<0.001)$, MIP-1beta/CCL4, and vascular endothelial growth factor $(\mathrm{VEGF}$; $<0.05)$ have also been implicated in RAS (138).

Treatment options are limited. There are reports of measured success using ECP. A subset of patients with higher BAL neutrophilia and RAS may have a better response with ECP $(139,140)$. Pirfenidone, an antifibrotic agent influencing production of transforming growth factor $\beta$ (TGF- $\beta$ may attenuate the decline in lung function. Translation of the physiologic benefit to clinical improvement, however, warrants further investigation (141). The CD52 antagonist, alemtuzumab, has been utilized with some success in case reports and small series of CLAD patients with rapid decline in lung function. Randomized trials are needed to better establish efficacy and safety $(142,143)$. Patients with RAS suffer far worse 1- and 3-year survival rates $(\mathrm{HR}=2.6)$ following re-transplantation compared to BOS patients (144). The decision to re- transplant these patients should be critically discussed, especially when other risk factors are present.

Neutrophil reversible allograft dysfunction (NRAD), later renamed azithromycin reversible allograft dysfunction (ARAD), encompasses a subset of patients diagnosed with CLAD who show exquisite sensitivity to macrolide therapy, some improving dramatically to no longer meeting criteria for CLAD (145).

This phenotype presents with high BAL neutrophils (>20\%), decline in FEV1 of at least $10 \%$, coarse crackles on physical exam, increased sputum production, and with tree-in-bud, centrilobular nodules and bronchiectasis on chest CT. The pathology of ARAD is not fully known. There are pathologic and immunologic similarities between lymphocytic bronchiolitis and ARAD. Both conditions have BAL neutrophilia and lymphocytic inflammation on biopsy and both are poorly responsive to steroid therapy (146).

\section{Conclusions}

Despite the minefield of possible complications after LT, outcomes and prognosis for 1-year survival have improved spectacularly over the past 2 decades. The greatest future challenge will be to improve long-term survival. Success in this area will rely heavily on our ability to prevent or treat CLAD.

\section{Acknowledgments}

Funding: None.

\section{Footnote}

Provenance and Peer Review: This article was commissioned by the Guest Editor (George Makdisi) for the series "Lung Transplant: Current Status and Challenges" published in Current Challenges in Thoracic Surgery. The article has undergone peer review.

Reporting Checklist: The authors have completed the Narrative Review reporting checklist. Available at https:// ccts.amegroups.com/article/view/10.21037/ccts-20-174/rc

Conflicts of Interest: All authors have completed the ICMJE uniform disclosure form (available at https://ccts.amegroups. com/article/view/10.21037/ccts-20-174/coif). The series "Lung Transplant: Current Status and Challenges" was commissioned by the editorial office without any funding or 
sponsorship. The authors have no other conflicts of interest to declare.

Ethical Statement: The authors are accountable for all aspects of the work in ensuring that questions related to the accuracy or integrity of any part of the work are appropriately investigated and resolved.

Open Access Statement: This is an Open Access article distributed in accordance with the Creative Commons Attribution-NonCommercial-NoDerivs 4.0 International License (CC BY-NC-ND 4.0), which permits the noncommercial replication and distribution of the article with the strict proviso that no changes or edits are made and the original work is properly cited (including links to both the formal publication through the relevant DOI and the license). See: https://creativecommons.org/licenses/by-nc-nd/4.0/.

\section{References}

1. van der Mark SC, Hoek RAS, Hellemons ME. Developments in lung transplantation over the past decade. Eur Respir Rev 2020;29:190132.

2. San Juan R, Aguado JM, Lumbreras C, et al. Incidence, clinical characteristics and risk factors of late infection in solid organ transplant recipients: data from the RESITRA study group. Am J Transplant 2007;7:964-71.

3. Aguilar-Guisado M, Givalda J, Ussetti P, et al. Pneumonia after lung transplantation in the RESITRA Cohort: a multicenter prospective study. Am J Transplant 2007;7:1989-96.

4. Campos S, Caramori M, Teixeira R, et al. Bacterial and fungal pneumonias after lung transplantation. Transplant Proc 2008;40:822-4.

5. Valentine VG, Bonvillain RW, Gupta MR, et al. Infections in lung allograft recipients: ganciclovir era. J Heart Lung Transplant 2008;27:528-35.

6. Parada MT, Alba A, Sepulveda C. Bronchiolitis obliterans syndrome development in lung transplantation patients. Transplant Proc 2010;42:331-2.

7. Yusen RD, Edwards LB, Dipchand AI, et al. The Registry of the International Society for Heart and Lung Transplantation: Thirty-third Adult Lung and HeartLung Transplant Report-2016; Focus Theme: Primary Diagnostic Indications for Transplant. J Heart Lung Transplant 2016;35:1170-84.

8. Alexander BD, Tapson VF. Infectious complications of lung transplantation. Transpl Infect Dis 2001;3:128-37.
9. Speich R, van der Bij W. Epidemiology and management of infections after lung transplantation. Clin Infect Dis 2001;33 Suppl 1:S58-65.

10. Patel R, Paya CV. Infections in solid-organ transplant recipients. Clin Microbiol Rev 1997;10:86-124.

11. Fishman JA. Infection in solid-organ transplant recipients. N Engl J Med 2007;357:2601-14.

12. Wahidi MM, Willner DA, Snyder LD, et al. Diagnosis and outcome of early pleural space infection following lung transplantation. Chest 2009;135:484-91.

13. de Bruyn G, Whelan TP, Mulligan MS, et al. Invasive pneumococcal infections in adult lung transplant recipients. Am J Transplant 2004;4:1366-71.

14. Maurer JR, Tullis DE, Grossman RF, et al. Infectious complications following isolated lung transplantation. Chest 1992;101:1056-9.

15. Deusch E, End A, Grimm M, et al. Early bacterial infections in lung transplant recipients. Chest 1993;104:1412-6.

16. Shteinberg M, Raviv Y, Bishara J, et al. The impact of fluoroquinolone resistance of Gram-negative bacteria in respiratory secretions on the outcome of lung transplant (non-cystic fibrosis) recipients. Clin Transplant 2012;26:884-90.

17. Dobbin C, Maley M, Harkness J, et al. The impact of pan-resistant bacterial pathogens on survival after lung transplantation in cystic fibrosis: results from a single large referral centre. J Hosp Infect 2004;56:277-82.

18. Aris RM, Gilligan PH, Neuringer IP, et al. The effects of panresistant bacteria in cystic fibrosis patients on lung transplant outcome. Am J Respir Crit Care Med 1997;155:1699-704.

19. Cunha C, Kurzai O, Carvalho A. PTX3 deficiency and aspergillosis. N Engl J Med 2014;370:1666-7.

20. Aris RM, Routh JC, LiPuma JJ, et al. Lung transplantation for cystic fibrosis patients with Burkholderia cepacia complex. Survival linked to genomovar type. Am J Respir Crit Care Med 2001;164:2102-6.

21. de Souza Carraro D, Carraro RM, Campos SV, et al. Burkholderia cepacia, cystic fibrosis and outcomes following lung transplantation: experiences from a single center in Brazil. Clinics (Sao Paulo) 2018;73:e166.

22. Doucette K, Fishman JA. Nontuberculous mycobacterial infection in hematopoietic stem cell and solid organ transplant recipients. Clin Infect Dis 2004;38:1428-39.

23. Husain S, McCurry K, Dauber J, et al. Nocardia infection in lung transplant recipients. J Heart Lung Transplant 2002;21:354-9. 
24. Burguete SR, Maselli DJ, Fernandez JF, et al. Lung transplant infection. Respirology 2013;18:22-38.

25. Kumar D, Husain S, Chen MH, et al. A prospective molecular surveillance study evaluating the clinical impact of community-acquired respiratory viruses in lung transplant recipients. Transplantation 2010;89:1028-33.

26. Gottlieb J, Schulz TF, Welte T, et al. Communityacquired respiratory viral infections in lung transplant recipients: a single season cohort study. Transplantation 2009;87:1530-7.

27. Astegiano S, Bergallo M, Solidoro P, et al. Prevalence and clinical impact of polyomaviruses $\mathrm{KI}$ and $\mathrm{WU}$ in lung transplant recipients. Transplant Proc 2010;42:1275-8.

28. Kaiser L, Aubert JD, Pache JC, et al. Chronic rhinoviral infection in lung transplant recipients. Am J Respir Crit Care Med 2006;174:1392-9.

29. Khalifah AP, Hachem RR, Chakinala MM, et al. Respiratory viral infections are a distinct risk for bronchiolitis obliterans syndrome and death. Am J Respir Crit Care Med 2004;170:181-7.

30. Milstone AP, Brumble LM, Barnes J, et al. A single-season prospective study of respiratory viral infections in lung transplant recipients. Eur Respir J 2006;28:131-7.

31. Liu M, Worley S, Arrigain S, et al. Respiratory viral infections within one year after pediatric lung transplant. Transpl Infect Dis 2009;11:304-12.

32. Bridevaux PO, Aubert JD, Soccal PM, et al. Incidence and outcomes of respiratory viral infections in lung transplant recipients: a prospective study. Thorax 2014;69:32-8.

33. Soccal PM, Aubert JD, Bridevaux PO, et al. Upper and lower respiratory tract viral infections and acute graft rejection in lung transplant recipients. Clin Infect Dis 2010;51:163-70.

34. Bridges ND, Spray TL, Collins MH, et al. Adenovirus infection in the lung results in graft failure after lung transplantation. J Thorac Cardiovasc Surg 1998;116:617-23.

35. Billings JL, Hertz MI, Savik K, et al. Respiratory viruses and chronic rejection in lung transplant recipients. J Heart Lung Transplant 2002;21:559-66.

36. Sayah DM, Koff JL, Leard LE, et al. Rhinovirus and other respiratory viruses exert different effects on lung allograft function that are not mediated through acute rejection. Clin Transplant 2013;27:E64-71.

37. Hopkins P, McNeil K, Kermeen F, et al. Human metapneumovirus in lung transplant recipients and comparison to respiratory syncytial virus. Am J Respir Crit Care Med 2008;178:876-81.

38. Kumar D, Michaels MG, Morris MI, et al. Outcomes from pandemic influenza A H1N1 infection in recipients of solid-organ transplants: a multicentre cohort study. Lancet Infect Dis 2010;10:521-6.

39. Glanville AR, Scott AI, Morton JM, et al. Intravenous ribavirin is a safe and cost-effective treatment for respiratory syncytial virus infection after lung transplantation. J Heart Lung Transplant 2005;24:2114-9.

40. Li L, Avery R, Budev M, et al. Oral versus inhaled ribavirin therapy for respiratory syncytial virus infection after lung transplantation. J Heart Lung Transplant 2012;31:839-44.

41. Permpalung N, Mahoney MV, McCoy C, et al. Clinical characteristics and treatment outcomes among respiratory syncytial virus (RSV)-infected hematologic malignancy and hematopoietic stem cell transplant recipients receiving palivizumab. Leuk Lymphoma 2019;60:85-91.

42. Gottlieb J, Zamora MR, Hodges T, et al. ALN-RSV01 for prevention of bronchiolitis obliterans syndrome after respiratory syncytial virus infection in lung transplant recipients. J Heart Lung Transplant 2016;35:213-21.

43. Doan ML, Mallory GB, Kaplan SL, et al. Treatment of adenovirus pneumonia with cidofovir in pediatric lung transplant recipients. J Heart Lung Transplant 2007;26:883-9.

44. Mitsani D, Nguyen MH, Girnita DM, et al. A polymorphism linked to elevated levels of interferongamma is associated with an increased risk of cytomegalovirus disease among Caucasian lung transplant recipients at a single center. J Heart Lung Transplant 2011;30:523-9.

45. Palmer SM, Limaye AP, Banks M, et al. Extended valganciclovir prophylaxis to prevent cytomegalovirus after lung transplantation: a randomized, controlled trial. Ann Intern Med 2010;152:761-9.

46. Humar A, Kumar D, Preiksaitis J, et al. A trial of valganciclovir prophylaxis for cytomegalovirus prevention in lung transplant recipients. Am J Transplant 2005;5:1462-8.

47. Manuel O, Kumar D, Moussa G, et al. Lack of association between beta-herpesvirus infection and bronchiolitis obliterans syndrome in lung transplant recipients in the era of antiviral prophylaxis. Transplantation 2009;87:719-25.

48. Paraskeva M, Bailey M, Levvey BJ, et al. Cytomegalovirus replication within the lung allograft is associated with bronchiolitis obliterans syndrome. Am J Transplant 2011;11:2190-6.

49. Johansson I, Martensson G, Nystrom U, et al. Lower incidence of CMV infection and acute rejections with valganciclovir prophylaxis in lung transplant recipients. 
BMC Infect Dis 2013;13:582.

50. Zamora MR, Nicolls MR, Hodges TN, et al. Following universal prophylaxis with intravenous ganciclovir and cytomegalovirus immune globulin, valganciclovir is safe and effective for prevention of CMV infection following lung transplantation. Am J Transplant 2004;4:1635-42.

51. Kotton CN, Kumar D, Caliendo AM, et al. Updated international consensus guidelines on the management of cytomegalovirus in solid-organ transplantation. Transplantation 2013;96:333-60.

52. Kiser TH, Fish DN, Zamora MR. Evaluation of valganciclovir pharmacokinetics in lung transplant recipients. J Heart Lung Transplant 2012;31:159-66.

53. Veit T, Munker D, Kauke T, et al. Letermovir for Difficult to Treat Cytomegalovirus Infection in Lung Transplant Recipients. Transplantation 2020;104:410-4.

54. Marty FM, Winston DJ, Chemaly RF, et al. A Randomized, Double-Blind, Placebo-Controlled Phase 3 Trial of Oral Brincidofovir for Cytomegalovirus Prophylaxis in Allogeneic Hematopoietic Cell Transplantation. Biol Blood Marrow Transplant 2019;25:369-81.

55. Shendi AM, Hung RKY, Caplin B, et al. The use of sirolimus in patients with recurrent cytomegalovirus infection after kidney transplantation: A retrospective case series analysis. Saudi J Kidney Dis Transpl 2019;30:606-14.

56. Green M, Michaels MG. Epstein-Barr virus infection and posttransplant lymphoproliferative disorder. Am J Transplant 2013;13 Suppl 3:41-54; quiz

57. Sampaio MS, Cho YW, Qazi Y, et al. Posttransplant malignancies in solid organ adult recipients: an analysis of the U.S. National Transplant Database. Transplantation 2012;94:990-8.

58. Kirk AD, Cherikh WS, Ring M, et al. Dissociation of depletional induction and posttransplant lymphoproliferative disease in kidney recipients treated with alemtuzumab. Am J Transplant 2007;7:2619-25.

59. Cen O, Longnecker R. Rapamycin reverses splenomegaly and inhibits tumor development in a transgenic model of Epstein-Barr virus-related Burkitt's lymphoma. Mol Cancer Ther 2011;10:679-86.

60. Zhu CY, Zhao SS, Wang XK, et al. Outcome of RituximabBased Treatment for Post-Transplant Lymphoproliferative Disorder After Allogeneic Hematopoietic Stem Cell Transplantation: A Single-Center Experience. Ann Transplant 2019;24:175-84.

61. Haque T, Wilkie GM, Jones MM, et al. Allogeneic cytotoxic T-cell therapy for EBV-positive posttransplantation lymphoproliferative disease: results of a phase 2 multicenter clinical trial. Blood 2007;110:1123-31.

62. Pappas PG, Andes D, Schuster M, et al. Invasive fungal infections in low-risk liver transplant recipients: a multicenter prospective observational study. Am J Transplant 2006;6:386-91.

63. Helmi M, Love RB, Welter D, et al. Aspergillus infection in lung transplant recipients with cystic fibrosis: risk factors and outcomes comparison to other types of transplant recipients. Chest 2003;123:800-8.

64. Doligalski CT, Benedict K, Cleveland AA, et al. Epidemiology of invasive mold infections in lung transplant recipients. Am J Transplant 2014;14:1328-33.

65. Cahill BC, Hibbs JR, Savik K, et al. Aspergillus airway colonization and invasive disease after lung transplantation. Chest 1997;112:1160-4.

66. Weigt SS, Copeland CAF, Derhovanessian A, et al. Colonization with small conidia Aspergillus species is associated with bronchiolitis obliterans syndrome: a twocenter validation study. Am J Transplant 2013;13:919-27.

67. Weigt SS, Elashoff RM, Huang C, et al. Aspergillus colonization of the lung allograft is a risk factor for bronchiolitis obliterans syndrome. Am J Transplant 2009;9:1903-11.

68. Singh N, Husain S. Aspergillus infections after lung transplantation: clinical differences in type of transplant and implications for management. J Heart Lung Transplant 2003;22:258-66.

69. Husain S, Mooney ML, Danziger-Isakov L, et al. A 2010 working formulation for the standardization of definitions of infections in cardiothoracic transplant recipients. J Heart Lung Transplant 2011;30:361-74.

70. Lin SJ, Schranz J, Teutsch SM. Aspergillosis case-fatality rate: systematic review of the literature. Clin Infect Dis 2001;32:358-66.

71. Hartmann T, Dumig M, Jaber BM, et al. Validation of a self-excising marker in the human pathogen Aspergillus fumigatus by employing the beta-rec/six sitespecific recombination system. Appl Environ Microbiol 2010;76:6313-7.

72. Donnelly JP, Chen SC, Kauffman CA, et al. Revision and Update of the Consensus Definitions of Invasive Fungal Disease From the European Organization for Research and Treatment of Cancer and the Mycoses Study Group Education and Research Consortium. Clin Infect Dis 2020;71:1367-76.

73. Gazzoni FF, Hochhegger B, Severo LC, et al. High- 
resolution computed tomographic findings of Aspergillus infection in lung transplant patients. Eur J Radiol 2014;83:79-83.

74. Herbrecht R, Denning DW, Patterson TF, et al. Voriconazole versus amphotericin B for primary therapy of invasive aspergillosis. N Engl J Med 2002;347:408-15.

75. Pfaller MA. Antifungal susceptibility testing: progress and future developments. Braz J Infect Dis 2000;4:55-60.

76. Sahi H, Avery RK, Minai OA, et al. Scedosporium apiospermum (Pseudoallescheria boydii) infection in lung transplant recipients. J Heart Lung Transplant 2007;26:350-6.

77. Cimon B, Carrere J, Vinatier JF, et al. Clinical significance of Scedosporium apiospermum in patients with cystic fibrosis. Eur J Clin Microbiol Infect Dis 2000;19:53-6.

78. Troke P, Aguirrebengoa K, Arteaga C, et al. Treatment of scedosporiosis with voriconazole: clinical experience with 107 patients. Antimicrob Agents Chemother 2008;52:1743-50.

79. Bhat SV, Paterson DL, Rinaldi MG, et al. Scedosporium prolificans brain abscess in a patient with chronic granulomatous disease: successful combination therapy with voriconazole and terbinafine. Scand J Infect Dis 2007;39:87-90.

80. Husain S, Munoz P, Forrest G, et al. Infections due to Scedosporium apiospermum and Scedosporium prolificans in transplant recipients: clinical characteristics and impact of antifungal agent therapy on outcome. Clin Infect Dis 2005;40:89-99.

81. Neofytos D, Fishman JA, Horn D, et al. Epidemiology and outcome of invasive fungal infections in solid organ transplant recipients. Transpl Infect Dis 2010;12:220-9.

82. Kulkarni HS, Cherikh WS, Chambers DC, et al. Bronchiolitis obliterans syndrome-free survival after lung transplantation: An International Society for Heart and Lung Transplantation Thoracic Transplant Registry analysis. J Heart Lung Transplant 2019;38:5-16.

83. Verleden SE, Vasilescu DM, McDonough JE, et al. Linking clinical phenotypes of chronic lung allograft dysfunction to changes in lung structure. Eur Respir J 2015;46:1430-9.

84. Vos R, Verleden SE, Verleden GM. Chronic lung allograft dysfunction: evolving practice. Curr Opin Organ Transplant 2015;20:483-91.

85. Verleden GM, Glanville AR, Lease ED, et al. Chronic lung allograft dysfunction: Definition, diagnostic criteria, and approaches to treatment-A consensus report from the Pulmonary Council of the ISHLT. J Heart Lung
Transplant 2019;38:493-503.

86. Todd JL, Palmer SM. Bronchiolitis obliterans syndrome: the final frontier for lung transplantation. Chest 2011;140:502-8.

87. Brugiere O, Pessione F, Thabut G, et al. Bronchiolitis obliterans syndrome after single-lung transplantation: impact of time to onset on functional pattern and survival. Chest 2002;121:1883-9.

88. Sato M, Ohmori-Matsuda K, Saito T, et al. Timedependent changes in the risk of death in pure bronchiolitis obliterans syndrome (BOS). J Heart Lung Transplant 2013;32:484-91.

89. Reynaud-Gaubert M, Thomas P, Badier M, et al. Early detection of airway involvement in obliterative bronchiolitis after lung transplantation. Functional and bronchoalveolar lavage cell findings. Am J Respir Crit Care Med 2000;161:1924-9.

90. Slebos DJ, Postma DS, Koeter GH, et al. Bronchoalveolar lavage fluid characteristics in acute and chronic lung transplant rejection. J Heart Lung Transplant 2004;23:532-40.

91. Hadjiliadis D, Davis RD, Palmer SM. Is transplant operation important in determining posttransplant risk of bronchiolitis obliterans syndrome in lung transplant recipients? Chest 2002;122:1168-75.

92. Heng D, Sharples LD, McNeil K, et al. Bronchiolitis obliterans syndrome: incidence, natural history, prognosis, and risk factors. J Heart Lung Transplant 1998;17:1255-63.

93. Keller CA, Cagle PT, Brown RW, et al. Bronchiolitis obliterans in recipients of single, double, and heart-lung transplantation. Chest 1995;107:973-80.

94. Sharples LD, McNeil K, Stewart S, et al. Risk factors for bronchiolitis obliterans: a systematic review of recent publications. J Heart Lung Transplant 2002;21:271-81.

95. Hachem RR, Khalifah AP, Chakinala MM, et al. The significance of a single episode of minimal acute rejection after lung transplantation. Transplantation 2005;80:1406-13.

96. Estenne M, Maurer JR, Boehler A, et al. Bronchiolitis obliterans syndrome 2001: an update of the diagnostic criteria. J Heart Lung Transplant 2002;21:297-310.

97. Burton CM, Iversen M, Scheike T, et al. Is lymphocytic bronchiolitis a marker of acute rejection? An analysis of 2,697 transbronchial biopsies after lung transplantation. J Heart Lung Transplant 2008;27:1128-34.

98. Goers TA, Ramachandran S, Aloush A, et al. De novo production of K-alpha1 tubulin-specific antibodies: role in chronic lung allograft rejection. J Immunol 
2008;180:4487-94.

99. Weber DJ, Wilkes DS. The role of autoimmunity in obliterative bronchiolitis after lung transplantation. Am J Physiol Lung Cell Mol Physiol 2013;304:L307-11.

100.Keenan RJ, Lega ME, Dummer JS, et al. Cytomegalovirus serologic status and postoperative infection correlated with risk of developing chronic rejection after pulmonary transplantation. Transplantation 1991;51:433-8.

101. Valentine VG, Gupta MR, Walker JE Jr, et al. Effect of etiology and timing of respiratory tract infections on development of bronchiolitis obliterans syndrome. J Heart Lung Transplant 2009;28:163-9.

102. Neurohr C, Huppmann P, Samweber B, et al. Prognostic value of bronchoalveolar lavage neutrophilia in stable lung transplant recipients. J Heart Lung Transplant 2009;28:468-74.

103. Reynaud-Gaubert M, Marin V, Thirion X, et al. Upregulation of chemokines in bronchoalveolar lavage fluid as a predictive marker of post-transplant airway obliteration. J Heart Lung Transplant 2002;21:721-30.

104. Scholma J, Slebos DJ, Boezen HM, et al. Eosinophilic granulocytes and interleukin-6 level in bronchoalveolar lavage fluid are associated with the development of obliterative bronchiolitis after lung transplantation. Am J Respir Crit Care Med 2000;162:2221-5.

105. Madill J, Aghdassi E, Arendt B, et al. Lung transplantation: does oxidative stress contribute to the development of bronchiolitis obliterans syndrome? Transplant Rev (Orlando) 2009;23:103-10.

106. Madill J, Aghdassi E, Arendt BM, et al. Oxidative stress and nutritional intakes in lung patients with bronchiolitis obliterans syndrome. Transplant Proc 2009;41:3838-44.

107. Riise GC, Andersson BA, Kjellstrom C, et al. Persistent high BAL fluid granulocyte activation marker levels as early indicators of bronchiolitis obliterans after lung transplant. Eur Respir J 1999;14:1123-30.

108. Berstad AE, Aalokken TM, Kolbenstvedt A, et al. Performance of long-term CT monitoring in diagnosing bronchiolitis obliterans after lung transplantation. Eur J Radiol 2006;58:124-31.

109. Collins J. Imaging of the chest after lung transplantation. J Thorac Imaging 2002;17:102-12.

110.Konen E, Gutierrez C, Chaparro C, et al. Bronchiolitis obliterans syndrome in lung transplant recipients: can thin-section CT findings predict disease before its clinical appearance? Radiology 2004;231:467-73.

111.Lee ES, Gotway MB, Reddy GP, et al. Early bronchiolitis obliterans following lung transplantation: accuracy of expiratory thin-section CT for diagnosis. Radiology 2000;216:472-7.

112.Leung AN, Fisher K, Valentine V, et al. Bronchiolitis obliterans after lung transplantation: detection using expiratory HRCT. Chest 1998;113:365-70.

113. Sarahrudi K, Estenne M, Corris P, et al. International experience with conversion from cyclosporine to tacrolimus for acute and chronic lung allograft rejection. J Thorac Cardiovasc Surg 2004;127:1126-32.

114. Gottlieb J, Szangolies J, Koehnlein T, et al. Long-term azithromycin for bronchiolitis obliterans syndrome after lung transplantation. Transplantation 2008;85:36-41.

115. Vos R, Vanaudenaerde BM, Verleden SE, et al. A randomised controlled trial of azithromycin to prevent chronic rejection after lung transplantation. Eur Respir J 2011;37:164-72.

116. Young LR, Hadjiliadis D, Davis RD, et al. Lung transplantation exacerbates gastroesophageal reflux disease. Chest 2003;124:1689-93.

117. Sweet MP, Herbella FA, Leard L, et al. The prevalence of distal and proximal gastroesophageal reflux in patients awaiting lung transplantation. Ann Surg 2006;244:491-7.

118.Davis RD Jr, Lau CL, Eubanks S, et al. Improved lung allograft function after fundoplication in patients with gastroesophageal reflux disease undergoing lung transplantation. J Thorac Cardiovasc Surg 2003;125:533-42.

119. Cantu E 3rd, Appel JZ 3rd, Hartwig MG, et al. J. Maxwell Chamberlain Memorial Paper. Early fundoplication prevents chronic allograft dysfunction in patients with gastroesophageal reflux disease. Ann Thorac Surg 2004;78:1142-51; discussion 1151.

120.Akesson A, Wollheim FA. Organ manifestations in 100 patients with progressive systemic sclerosis: a comparison between the CREST syndrome and diffuse scleroderma. Br J Rheumatol 1989;28:281-6.

121.Hoppo T, Jarido V, Pennathur A, et al. Antireflux surgery preserves lung function in patients with gastroesophageal reflux disease and end-stage lung disease before and after lung transplantation. Arch Surg 2011;146:1041-7.

122. Richardson CB, Singer JP. Lung Transplantation for Scleroderma-related Lung Disease. Curr Respir Care Rep 2014;3:79-87.

123. Reams BD, Musselwhite LW, Zaas DW, et al. Alemtuzumab in the treatment of refractory acute rejection and bronchiolitis obliterans syndrome after human lung transplantation. Am J Transplant 2007;7:2802-8.

124. Shyu S, Dew MA, Pilewski JM, et al. Five-year outcomes 
with alemtuzumab induction after lung transplantation. J

Heart Lung Transplant 2011;30:743-54.

125. Fisher AJ, Rutherford RM, Bozzino J, et al. The safety and efficacy of total lymphoid irradiation in progressive bronchiolitis obliterans syndrome after lung transplantation. Am J Transplant 2005;5:537-43.

126. Diamond DA, Michalski JM, Lynch JP, et al. Efficacy of total lymphoid irradiation for chronic allograft rejection following bilateral lung transplantation. Int J Radiat Oncol Biol Phys 1998;41:795-800.

127. Verleden GM, Lievens Y, Dupont LJ, et al. Efficacy of total lymphoid irradiation in azithromycin nonresponsive chronic allograft rejection after lung transplantation. Transplant Proc 2009;41:1816-20.

128. Meloni F, Cascina A, Miserere S, et al. Peripheral CD4(+)CD25(+) TREG cell counts and the response to extracorporeal photopheresis in lung transplant recipients. Transplant Proc 2007;39:213-7.

129. Hachem R, Corris P. Extracorporeal Photopheresis for Bronchiolitis Obliterans Syndrome After Lung Transplantation. Transplantation 2018;102:1059-65.

130. Vos R, Eynde RV, Ruttens D, et al. Montelukast in chronic lung allograft dysfunction after lung transplantation. J Heart Lung Transplant 2019;38:516-27.

131. Hall DJ, Belli EV, Gregg JA, et al. Two Decades of Lung Retransplantation: A Single-Center Experience. Ann Thorac Surg 2017;103:1076-83.

132. Novick RJ, Schafers HJ, Stitt L, et al. Recurrence of obliterative bronchiolitis and determinants of outcome in 139 pulmonary retransplant recipients. J Thorac Cardiovasc Surg 1995;110:1402-13; discussion 13-4.

133. Yousem SA, Burke CM, Billingham ME. Pathologic pulmonary alterations in long-term human heart-lung transplantation. Hum Pathol 1985;16:911-23.

134. Martinu T, Howell DN, Davis RD, et al. Pathologic correlates of bronchiolitis obliterans syndrome in pulmonary retransplant recipients. Chest 2006;129:1016-23.

135.Pakhale SS, Hadjiliadis D, Howell DN, et al. Upper lobe fibrosis: a novel manifestation of chronic allograft dysfunction in lung transplantation. J Heart Lung Transplant 2005;24:1260-8.

136. Sato M, Waddell TK, Wagnetz U, et al. Restrictive

doi: $10.21037 /$ ccts-20-174

Cite this article as: Erasmus DB, Narula T, Khoor A. Chronic and long-term complications after lung transplant: a narrative review. Curr Chall Thorac Surg 2021. allograft syndrome (RAS): a novel form of chronic lung allograft dysfunction. J Heart Lung Transplant 2011;30:735-42.

137. Verleden SE, Ruttens D, Vandermeulen E, et al. Bronchiolitis obliterans syndrome and restrictive allograft syndrome: do risk factors differ? Transplantation 2013;95:1167-72.

138. Verleden SE, Ruttens D, Vos R, et al. Differential cytokine, chemokine and growth factor expression in phenotypes of chronic lung allograft dysfunction. Transplantation 2015;99:86-93.

139.Greer M, Dierich M, De Wall C, et al. Phenotyping established chronic lung allograft dysfunction predicts extracorporeal photopheresis response in lung transplant patients. Am J Transplant 2013;13:911-8.

140. Del Fante C, Scudeller L, Oggionni T, et al. Long-Term Off-Line Extracorporeal Photochemotherapy in Patients with Chronic Lung Allograft Rejection Not Responsive to Conventional Treatment: A 10-Year Single-Centre Analysis. Respiration 2015;90:118-28.

141. Vos R, Wuyts WA, Gheysens O, et al. Pirfenidone in restrictive allograft syndrome after lung transplantation: A case series. Am J Transplant 2018;18:3045-59.

142. Kohno M, Perch M, Andersen E, et al. Treatment of intractable interstitial lung injury with alemtuzumab after lung transplantation. Transplant Proc 2011;43:1868-70.

143. Ruiz-Arguelles GJ, Ruiz-Delgado GJ, Moreno-Ford V. Re: Alemtuzumab-induced resolution of pulmonary noninfectious complications in a patient with chronic graft-versus-host disease. Biol Blood Marrow Transplant 2008;14:1434-5.

144. Kawut SM. Lung retransplantation. Clin Chest Med 2011;32:367-77.

145. Vanaudenaerde BM, Meyts I, Vos R, et al. A dichotomy in bronchiolitis obliterans syndrome after lung transplantation revealed by azithromycin therapy. Eur Respir J 2008;32:832-43.

146. Chambers DC, Hodge S, Hodge G, et al. A novel approach to the assessment of lymphocytic bronchiolitis after lung transplantation--transbronchial brush. J Heart Lung Transplant 2011;30:544-51. 